\title{
Corrigendum \\ Predictors of Naltrexone Response in a Randomized Trial: Reward-Related Brain Activation, OPRMI Genotype, and Smoking Status
}

Joseph P Schacht, Patrick K Randall, Patricia K Latham, Konstantin E Voronin, Sarah W Book, Hugh Myrick and Raymond F Anton

Neuropsychopharmacology (2017) 42, 2654; doi:10.1038/npp.2017.I85

Correction to: Neuropsychopharmacology advance online publication, 17 May 2017; doi:10.1038/npp.2017.74

Following publication, the authors reported that the legends for Figures 3 and 4 were inadvertently switched. This error does not change the content, statistics, or conclusions of the report.

The correct legend for Figure 3 is: Percent heavy drinking days during the 16-week treatment period and the 24-week post-treatment follow-up by OPRM1 A118G genotype and medication group. Regression lines were fit separately for each period. The genotype by medication by time interaction was significant, such that G-allele carriers who received naltrexone had an increased rate of heavy drinking once medication was stopped, whereas the other groups did not. Figures are estimated marginal means \pm SE's.

The correct legend for Figure 4 is: Percent heavy drinking days by smoking status at study entry and medication group. There was a significant interaction between smoking, medication, and time, such that \%HDD increased over time among smokers, but not non-smokers, and naltrexone, relative to placebo, ablated this increase among smokers. Figures are estimated marginal means \pm SE's. $N$ 's indicate the number of subjects who provided drinking data at each time point. ${ }^{*} p<0.05$ for the simple effect of medication among smokers during each month. 